\title{
Fistulized Crohn’ Disease Mimicking Sigmoid Cancer: A Case Report
}

\author{
Bartu Badak (iD), Ercument Pasaoglu, Huseyin Tarik Caga, Enver Ihtiyar, Adnan Sahin, \\ Serdar Erkasap, Ersin Ates, Necdet Fatih Yasar
}

\begin{abstract}
Crohn's disease is an inflammatory bowel disease of unknown etiology, progressing with frequent exacerbation periods that can involve any part of the gastrointestinal tract. Although, it can manifest itself with complaints from the entire gastrointestinal tract; abdominal pain, diarrhea, nausea, weight loss and fever are the most important clinical symptoms. In this presentation, a 41-year-old male patient with known Crohn's disease was presented to our hospital with the help of operation images.
\end{abstract}

\section{Keywords}

Inflammatory; Disease; Gastrointestinal

Department of General Surgery, Eskisehir Osmangazi University, Eskisehir, Turkey

*Corresponding author: drbartu@gmail.com

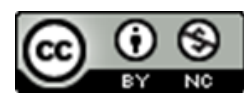

Copyright @Bartu Badak, Ercument Pasaoglu, Huseyin Tarik Caga, Enver Ihtiyar, Adnan Sahin, Serdar Erkasap, Ersin Ates, Necdet Fatih Yasar, 2020

\section{Introduction}

Crohn's disease is a chronic inflammatory disease with remission and exacerbation periods that is characterized by transmural inflammation that can involve any part of the gastrointestinal tract from the mouth to the anus [1]. This disease, the exact etiology of which is unknown, is generally diagnosed during adolescence. Abdominal pain, diarrhea, nausea, fever are the most common forms of clinical presentation [2]. Although perianal and enterocutaneous fistulas generally develop in Crohn's disease, fistulas to the urinary system are observed as well [3]. Patients with Crohn's disease confined to the colon often present with rectal bleeding, perianal complications, and extraintestinal symptoms involving the skin and joints [4]. It may be difficult to distinguish this group with colon-restricted disease from colon carcinomas [5]. In this case, we aimed to report our patient that he had ileus symptoms mimicking colon carcinoma.

\section{Case Report}

A 41-year-old male patient was admitted to our clinic due to swelling and a foul-smelling discharge in the operation area after he had been operated on for left inguinal hernia on the outer center. On examination of the patient, there was an incision scar in the left inguinal region and a foul-smelling discharge compatible with the intestinal contents coming from this area. There was no acute abdomen in the patient. We learned that he had Crohn's disease, which was followed up irregularly in the patient's history, and that he received last medical treatment about 2 years ago. According to outpatient surgery reports requested, he was operated on due to swelling in the left inguinal region; primary hernia repair was performed and he was referred for further examination. The patient had high levels of white blood cell and C-reactive protein. In abdominal computed tomography performed to determine the etiology, a fistulous tract extending to the skin by infiltrating the sigmoid colon lumen and oblique muscles leading to the obstruction in the lumen, possibly starting from the level of the rectosigmoid junction and extending over the 10-cm segment along the sigmoid colon, was detected (Fig. 1). Rectosigmoidoscopy was decided to be performed.

In rectosigmoidoscopy, after the lesion was covered with edematous necrotic material that did not allow the passage of the endoscope to the middle part of the sigmoid colon, biopsy was taken from this specimen and the procedure was terminated. Biopsy revealed that the patient's complaints were "activated chronic inflammation" and the decision to perform surgery was taken due to increasing obstructive symptoms. During surgery, the sigmoid colon was observed to invade the surrounding tissue and have intestinal contents and abscess 


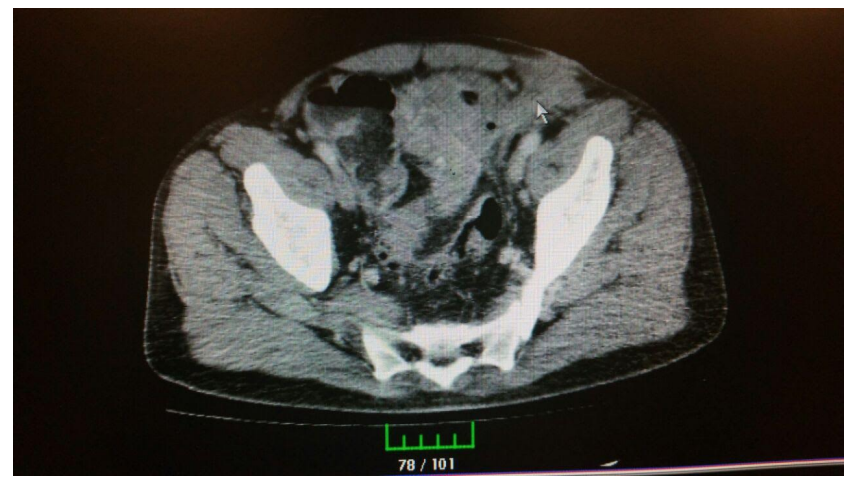

Figure 1. Fistulous tract.

contamination in the abdomen. A Hartmann's procedure was decided to be performed. The lesion in the sigmoid colon was observed to be fistulized from the mouth to the skin, bladder and terminal ileum. The state of the tract was also confirmed with methylene blue delivered to the bladder. The mass was unblocked, separated from the surrounding tissues by blunt and sharp dissections, and resected by partial cystectomy and segmental small bowel resection (Fig. 2). Surgery was completed without any complications.

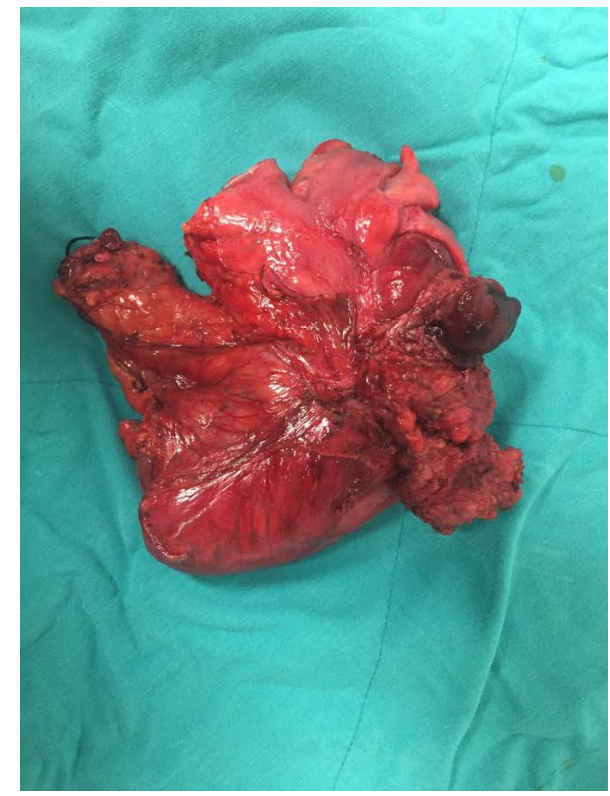

Figure 2. Mass resected by partial cystectomy and segmental small bowel resection.

The histopathological examination of the specimen revealed chronic active colitis, glandular distortion, destruction and cryptic abscesses in the colon. Inflammation was observed in all wall floors of the colon. There was inflammatory granulation tissue on the serosal surface. There was observed fistula formation. The findings were reported as those related to Crohn's disease. The patient, who was discharged after surgery, was directed to the gastroenterology department.

\section{Discussion and Conclusions}

Crohn' disease is a disease of unknown etiology characterized by granulomatous inflammation with healing and exacerbation periods that can involve any part of the gastrointestinal tract [1]. It most often manifests itself as abdominal pain, nausea, diarrhea and fever [2]. It tends to form fistulas to the skin and perianal region [3]. Imaging methods, especially computed tomography and endoscopic procedures, can be used in diagnosing Crohn's disease. Histopathological examination is absolutely necessary for definitive diagnosis. The type of treatment for Crohn' disease is determined by its severity, form and localization [6]. The goal of treatment is to clinically achieve remission. In medical treatment, immune system effective drugs such as sulfasalazine, mesalamine, cyclosporin, prednisolone, methotrexate, tacrolimus and various antibiotics can be used [6]. In complicated cases, such as obstruction, perforation, bleeding, surgery is inevitable. Postoperative abscess formation, sepsis, new fistula formation, anastomosis leaks, and ileus are possible postoperative complications [7]. There were fistulous tracts in 3 different locations of the diseased area in the sigmoid colon, which is interesting in our patient.

\section{Informed Consent}

Written informed consent was obtained from the patient who participated in this case.

\section{Conflict of Interest}

The authors declare that no conflicts exist.

\section{Financial Disclosure}

The authors declared no financial support.

\section{References}

[1] Cosnes A, Dupuy A, Revuz J, Delchier JC, Contou JF, Gendre JP, et al. Long-term evolution of oral localization of Crohn's disease. Gastroenterology [Internet]. 1998 Apr;114(1):A956. Available from: https://doi.org/10.1016/S0016-5085(98)83894-8

[2] Neville BW, Damm DD, Allen CM et al. Oral and maxillofacial pathology. 2nd edn. Philadelphia: Saunders; 2002.

[3] Solem CA, Loftus E V, Tremaine WJ, Pemberton JH, Wolff BG, Sandborn WJ. Fistulas to the urinary system in Crohn's disease: clinical features and outcomes. Am J Gastroenterol [Internet]. 2002 Sep;97(9):2300-5. Available from: https://doi.org/10.1111/j.1572-0241.2002.05983.x [PMid:12358248]

[4] Platell C, Mackay J, Collopy B, Fink R, Ryan P, Woods R. Anal pathology in patients with crohn's disease. ANZ J Surg [Internet]. 1996 Jan;66(1):5-9. Available from: 
https://doi.org/10.1111/j.1445-2197.1996.tb00690.x [PMid:8629983]

[5] Lapidus A, Bernell O, Hellers G, Löfberg R. Clinical course of colorectal Crohn's disease: A 35year follow-up study of 507 patients. Gastroenterology [Internet]. 1998 Jun;114(6):1151-60. Available from: https://doi.org/10.1016/S0016-5085(98)70420-2

[6] Kuzu A. Crohn Hastalığ 1 [Internet]. 2015 [cited 2020 May 29]. Available from: https://www.kolonrektum.com/crohn-hastaligi
[7] Manganiotis AN, Banner MP, Malkowicz SB. Urologic Complications of Crohn's Disease. Surg Clin North Am [Internet]. 2001 Feb;81(1):197-215. Available from: https://doi.org/10.1016/S0039-6109(05)70281-4

Received: 2020-05-29

Revised: 2020-09-30

Accepted: 2020-10-01 